\title{
Loss of the mRNA-like region in mitochondrial tmRNAs of jakobids
}

\author{
YANNICK JACOB, ${ }^{2,3}$ ELIAS SEIF, ${ }^{2}$ PIERRE-OLIVIER PAQUET, ${ }^{2}$ and B. FRANZ LANG ${ }^{1,2}$ \\ ${ }^{1}$ Program in Evolutionary Biology, Canadian Institute for Advanced Research \\ ${ }^{2}$ Département de Biochimie, Université de Montréal, Montréal, Québec, Canada H3T 1J4
}

\begin{abstract}
It has been postulated that a highly reduced form of transfer messenger RNA (tmRNA), a bacterial molecule involved in the rescue of stalled ribosomes during translation, is expressed in the mitochondrion of the jakobid Reclinomonas americana. Here we show that genes encoding both one-piece and two-piece tmRNAs are present in six different jakobid mitochondrial DNAs. Mitochondrial tmRNAs have retained the highly conserved $t R N A^{\text {Ala }}$-like domain, but they apparently lack the mRNA-like region present in all bacterial tmRNAs. Comparative analysis of jakobid mitochondrial genomes shows that a potential mRNA-like region in $R$. americana (orf64) is located at distant genomic positions in other jakobids. Our results strongly suggest that orf64 is a tatA homolog. Through Northern hybridization we confirm the postulated reduced size of both a one-piece tmRNA in Jakoba libera and a two-piece tmRNA in Seculamonas ecuadoriensis. The $J$. libera tmRNA is post-transcriptionally modified by addition of a 3' CCA tail, processed in vitro by RNase P RNA, and specifically charged with alanine in vitro by alanyl-tRNA synthetase. Our results strongly support the functionality of these reduced mitochondrial tmRNAs.
\end{abstract}

Keywords: mitochondrial tmRNAs; jakobids; standard and permuted ssrA gene; orf64

\section{INTRODUCTION}

Genes encoding transfer-messenger RNAs ( $s s r A)$ are found in bacterial and chloroplast genomes (Williams 2002a). Two functions are associated to tmRNAs: reactivation of ribosomal translation complexes that are blocked by mRNAs without in-frame stop codons (e.g., partially degraded mRNAs), and signalization of the polypeptides for proteolysis (for review, see Karzai et al. 2000). Accordingly, bacterial tmRNAs are composed of two distinct structural elements: (1) a tRNA ${ }^{\text {Ala }}$-like domain responsible for the entry of the alanine-charged tmRNA to the A site of a stalled ribosome; and (2) an mRNA-like region, which codes for a hydrophobic signal peptide that is added to the end of the polypeptide once the stalled ribosome has switched from the original mRNA to the tmRNA reading frame (Keiler et al. 1996). When the ribosome reaches the stop codon of the tmRNA reading frame, translation is terminated, the polypeptide is released,

Reprint requests to: $B$. Franz Lang, Département de Biochimie, Université de Montréal, 2900 Boulevard Edouard Montpetit, Montréal, Québec, Canada H3T 1J4; e-mail: Franz.Lang@Umontreal.ca; fax: (514) 3432210.

${ }^{3}$ Present address: Department of Biology, Indiana University, $1001 \mathrm{E}$. Third St., Bloomington, IN 47405, USA.

Article and publication are at http://www.rnajournal.org/cgi/doi/ 10.1261/rna.5227904. and subsequently degraded by specific proteases that recognize the C-terminal signal peptide (referred to as "tag" in the following).

It was previously thought that $\alpha$-Proteobacteria was the only group of bacteria lacking a ssrA gene (Felden et al. 1999). However, the universality of tmRNAs in bacteria has been established with the identification of circularly permuted ssrA genes that code for two-piece tmRNAs in $\alpha$-Proteobacteria (Keiler et al. 2000). These variant tmRNAs, also present through an independent gene permutation event in a specific group of Cyanobacteria (Keiler et al. 2000; Gaudin et al. 2002), have been given the attribute "two-piece" (as opposed to standard or "one-piece" tmRNAs) because they are composed of two distinct RNA molecules: (1) the "coding RNA", which contains the tag reading frame and one part of the tRNA-like sequence, and (2) the acceptor RNA, which carries the other part of the tRNA-like structure that will have the alanine moiety attached at its $3^{\prime}$ end (see Fig. 2A below, Rickettsia prowazekii tmRNA).

The discovery of two-piece ssrA genes in $\alpha$-Proteobacteria, the closest known bacterial relatives of mitochondria, was immediately followed by the identification of a likewise circularly permuted ssrA gene in the mitochondrial genome of the jakobid-like flagellate Reclinomonas americana (strain ATCC 50394; Keiler et al. 2000). Jakobid-like flagellates are 
a group of free-living, bacterivorous protists (O’Kelly 1993). In taxonomic terms, they are subdivided into two families based on morphological and ultrastructural data: the Malawimonadidae (malawimonads), and the Jakobidae (jakobids; also known as "core jakobids"; O’Kelly et al. 1999). Jakobid cells have a single mitochondrion, and the most gene-rich and bacterial-like mitochondrial DNA of all eukaryotic cells (Lang et al. 1997; B.F. Lang and G. Burger, unpubl.). As we will show, mitochondrial ssrA genes are conserved in the jakobid family, which includes the genera Jakoba, Reclinomonas, Histiona, and Seculamonas.

The tmRNA homolog encoded by the mitochondrial ssrA gene of $R$. americana has the typical tRNA ${ }^{\text {Ala }}$-like domain, but it appears to have lost the mRNA-like region because a typical tag reading frame has not been found (Keiler et al. 2000). Loss of structural elements characteristic of bacterial tmRNAs has been observed in other endosymbiont tmRNAs (Gueneau de Novoa and Williams 2004), but $R$. americana tmRNA would be the only one to lack a tag reading frame. In the mitochondrial genome of $R$. americana, the sequence coding for the tRNA ${ }^{\text {Ala }}$-like domain is immediately followed by an open reading frame encoding a putative, currently unidentified, protein of 64 amino acids preceded by a canonical Shine-Dalgarno sequence. By comparison with the genetic structure of two-piece bacterial tmRNA genes, the mRNA-like region of $R$. americana tmRNA should be encoded in the region of the mtDNA sequence corresponding to orf64.

Comparative analysis with other jakobid mitochondrial tmRNAs (mt-tmRNAs) would greatly help to define the conserved structural elements that might be important for the cellular role of these molecules, and to verify the possible genetic link between ssrA and orf64. To address these issues, we have identified five new jakobid mt-tmRNAs (in two additional R. americana strains, Histiona aroides, Seculamonas ecuadoriensis and Jakoba libera). Comparative and Northern blot analyses confirm that all jakobid mitochondrial tmRNAs have lost the mRNA-like region. We further show that J. libera tmRNA is expressed at the RNA level, processed, and post-transcriptionally modified with the addition of the CCA tail. Recognition and modification of this tmRNA in vitro by enzymes that interact with bacterial tmRNAs is also demonstrated. The function of these highly derived tmRNAs is discussed.

\section{RESULTS}

\section{One-piece and two-piece tmRNA genes in jakobid mitochondrial genomes}

Sequencing of jakobid mitochondrial DNAs (mtDNAs) has permitted the identification of five new mitochondrial ssrA genes (Fig. 1). Like in R. americana (strain ATCC 50394), these ssrA genes encode two-piece mt-tmRNAs, except for $J$. libera, which has a one-piece conformation.
Figure 1 shows the predicted secondary structures of all known mt-tmRNAs. The one-piece conformation of $\mathrm{J} . \mathrm{li}$ bera tmRNA allows a precise prediction of both the processing sites and the size of this RNA (102 nucleotides, including the post-transcriptionally added 3 ' CCA tail; Fig. $1)$. The two-piece mt-tmRNAs are expected to require at least four RNA processing steps; two, likely mediated by RNase $\mathrm{P}$ and a $3^{\prime}$ tRNA-like processing activities, to remove the intervening sequence (thus generating the two distinct RNAs of the two-piece tmRNAs); and two mechanistically undefined steps at the two opposite RNA termini. Prediction of the size of these mt-tmRNAs will require additional data from RNA mapping experiments.

The tRNA ${ }^{\text {Ala }}$-like domains of all mt-tmRNAs display the canonical features of the corresponding domains of eubacterial tmRNAs; most notably, a series of G residues at the 5' end, a G-U base pair at the third position of the acceptor stem, and an A residue at the discriminator position (Williams 2002a). Only the mt-tmRNA of S. ecuadoriensis lacks the G-U base pair at the third position of the acceptor stem. Other features shared between the $\mathrm{RNA}^{\mathrm{Ala}}$-like domains of bacterial and mitochondrial tmRNAs are the absence of a D stem, and the presence of a short (3 nt) variable loop. Like in the tmRNAs of their $\alpha$-proteobacterial relatives (Fig. 2A, $R$. prowazekii tmRNA), the mt-tmRNA sequences deviate in the T $\Psi \mathrm{C}$ loop from the conserved UUCRANY motif that is otherwise common in tRNAs and tmRNAs (Felden et al. 1998). In addition, the residues $G_{18}$ and $A_{19}$ of mt-tmRNAs (referring to the J. libera tmRNA numbering, Fig. 1) are universally conserved in bacterial tmRNAs (Williams 2002a). A mutation in this motif has been shown to inhibit the binding in vitro of the protein $\mathrm{SmpB}$ to Escherichia coli tmRNA (Hanawa-Suetsugu et al. 2002). SmpB binding is essential for the activity of bacterial tmRNAs (Karzai et al. 1999).

\section{Jakobid mt-tmRNAs have lost the mRNA-like region of eubacterial tmRNAs}

The small one-piece J. libera mt-tmRNA clearly does not include the mRNA-like region that is present in all eubacterial and plastid tmRNAs. For two-piece mt-tmRNAs, it remains to be shown whether or not an mRNA-like region is encoded downstream of the tRNA ${ }^{\text {Ala }}$-like domain.

In the mitochondrial genome of all three $R$. americana strains, a functionally unassigned ORF (orf64) follows the $3^{\prime}$ end of the tRNA ${ }^{\text {Ala }}$-like domain. A short AT-rich segment ( $\sim 50 \mathrm{nt}$ in $R$. americana 50394 tmRNA) separates the predicted Shine-Dalgarno sequence preceding orf 64 and the tRNA ${ }^{\mathrm{Ala}}$-like domain (Fig. 2A, R. americana 50394 tmRNA). For $R$. americana tmRNAs to have an mRNAlike domain, orf64 would have to be genetically included, either partially or completely, into the two-piece tmRNA genes based on the genetic structure of two-piece bacterial tmRNAs. Our analyses of the mitochondrial gene organi- 


\section{Reclinomonas americana 50394}
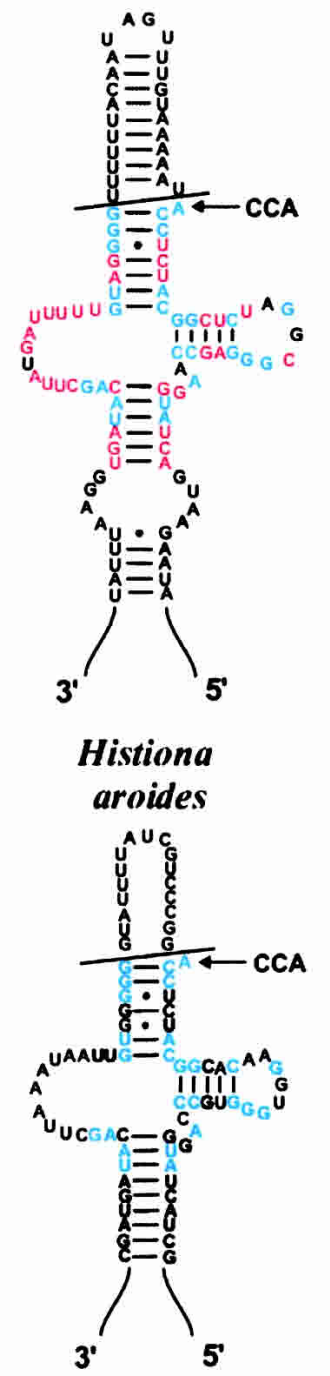
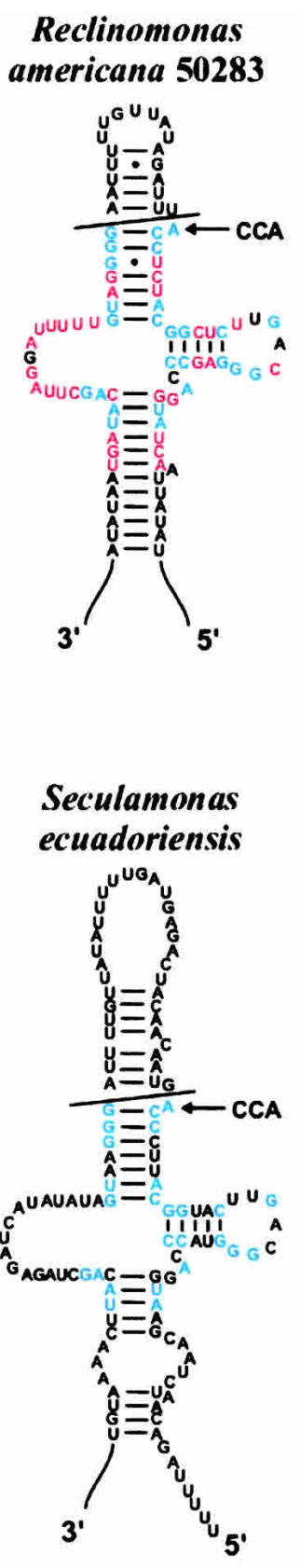

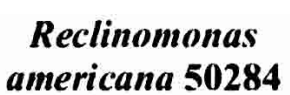
americana 50284
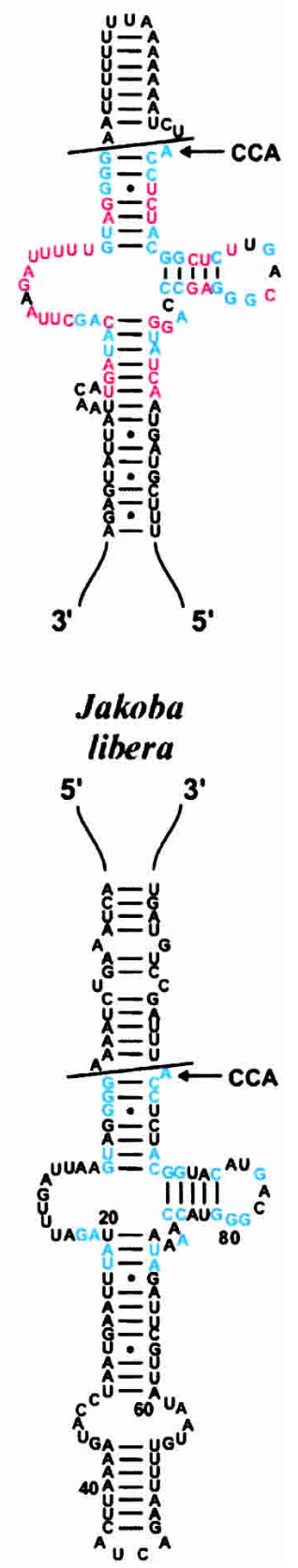

FIGURE 1. Predicted secondary structure of the tRNA ${ }^{\text {Ala }}$-like domains of jakobid mitochondrial tmRNAs. All of the tmRNAs presented, except J. libera tmRNA, are in the two-piece conformation. The conservation of the primary structure between all mitochondrial tmRNAs (blue), and between the three R. americana tmRNAs (blue and red), is shown. Straight lines separate the sequences (known as intervening sequences in twopiece tmRNAs) that are expected to be cut during the processing of mt-tmRNAs. The mature $5^{\prime}$ and $3^{\prime}$ ends located below the tRNA ${ }^{\mathrm{Ala}}$-like domain are still unknown for twopiece mt-tmRNAs. Therefore, this region is represented by curved lines. The $5^{\prime}$ end of $S$. ecuadoriensis tmRNA shown here corresponds to the first nucleotide after the stop codon of the gene (rps2) located immediately upstream of the ssrA gene. The $3^{\prime}$ CCA tail is not encoded in the mitochondrial tmRNA genes and is therefore predicted to be posttranscriptionally added.

zation of jakobid species with two-piece tmRNAs show that $H$. aroides has an orf64 homolog located immediately downstream of its $s s r A$ gene (Fig. 2B). However, the orf64 homolog in S. ecuadoriensis is located upstream of the $s s r A$ gene, and a rps2 gene (ribosomal small subunit protein 2) is located between the orf64 homolog and the ssrA gene. These observations make it highly unlikely that orf64 encodes a derived mRNA-like region. To further demonstrate the genetic independence of $s s r A$ and orf64, we have searched the Orf64 amino acids sequence against public databases. Based on the results from this search, we conclude that orf64 codes for a TatA homolog. Tat proteins are implicated in the twin-arginine protein translocation pathway that requires both the TatA and TatC proteins for activity (Wu et al. 2000). tatC genes (also known as $m t t B$ ) have been identified in all jakobid mtDNAs (B.F. Lang and G. Burger, unpubl.), which is in line with our finding that orf64 is a tatA homolog.

A comparison of all mt-tmRNA sequences shows that the conservation of the primary structure is restricted to the tRNA $^{\text {Ala }}$-like domain (see color coding in Fig. 1). This could be an indication that the $5^{\prime}$ and $3^{\prime}$ termini of the mature twopiece mt-tmRNAs are adjacent to the regions of primary sequence similarity. Results from Northern blot analyses for $S$. ecuadoriensis mt-tmRNA validate this assumption, through identification of two small RNAs of $\sim 30 \mathrm{nt}$ and $\sim 40 \mathrm{nt}$, corresponding to the coding RNA and the acceptor RNA, respectively (data not shown). These results confirm the small size of the two-piece mt-tmRNA of $S$. ecuadoriensis, and the absence of an mRNA-like domain.

\section{J. libera mt-tmRNA is processed at the expected nucleotide positions}

To determine if mt-tmRNAs are processed at the expected nucleotide positions (see straight lines in Fig. 1), we have chosen the experimentally simplest onepiece mt-tmRNA of J. libera as a model. A stable mt-tmRNA transcript of $\sim 100 \mathrm{nt}$ was identified in J. libera by Northern 
A Rickettsia prowazekii
Q-proteobacterial tmRNA Reclinomonas
americana 50394

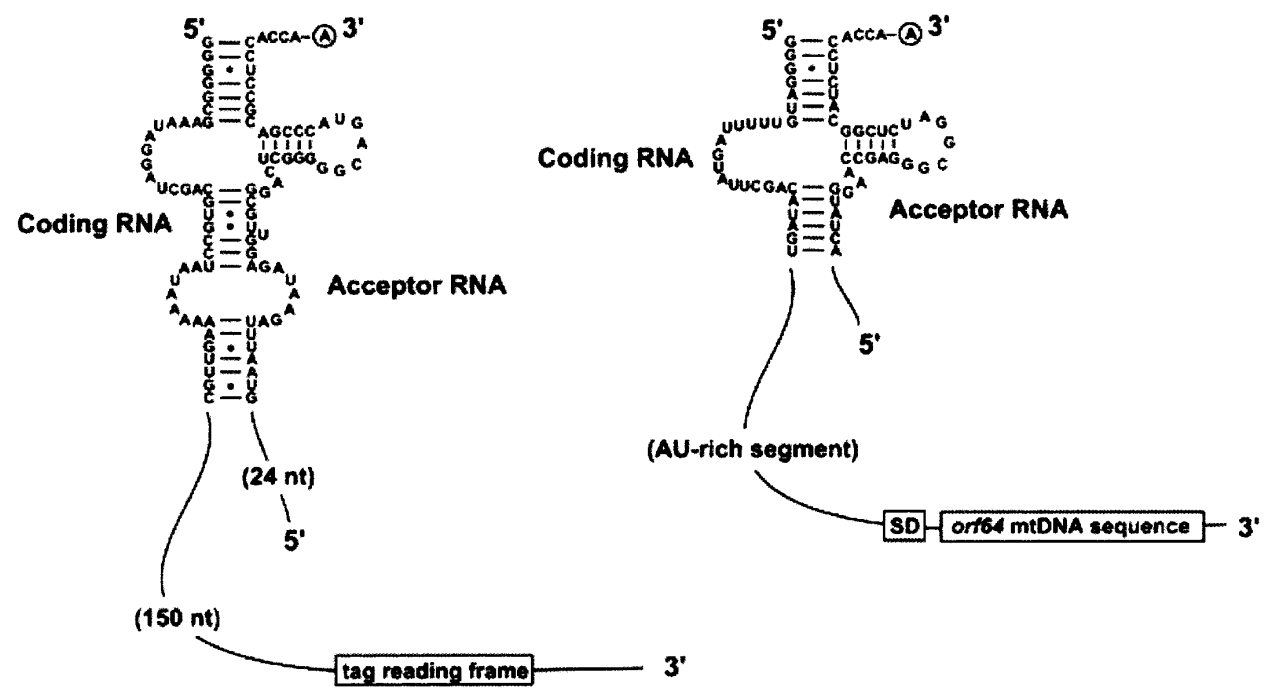

B

R. americana

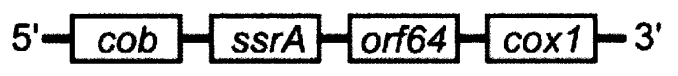

H. aroides

$5^{\prime}$ cob ssrA orf64 cox1-3'

S. ecuadoriensis

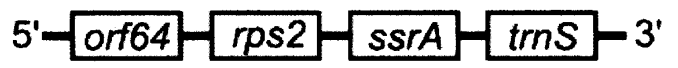

FIGURE 2. Verification of the potential genetic link between $s s r A$ and orf64. (A) Based on the structure of bacterial two-piece tmRNAs (e.g., $R$. prowazekii tmRNA), the mRNA-like region of $R$. americana mt-tmRNAs (e.g., $R$. americana 50394) should be present in the mtDNA sequence assigned to the functionally uncharacterized orf64. SD: predicted Shine-Dalgarno sequence of orf64. (B) The presence of an orf64 homolog immediately downstream of the $s s r A$ gene is conserved between $R$. americana and $H$. aroides. However, this mitochondrial gene organization is different in S. ecuadoriensis because orf64 is upstream of $s s r A$ and separated from it by rps2 (ribosomal small subunit protein 2). The mitochondrial gene organization in S. ecuadoriensis does not support the hypothesis that the orf64 mtDNA sequences encode the mRNA-like domains of the two-piece mt-tmRNA genes of jakobids.

blot analysis (Fig. 3A). This is consistent with the expected size of the mt-tmRNA if it processed at the $5^{\prime}$ and $3^{\prime}$ ends to generate a mature tRNA ${ }^{\mathrm{Ala}}$-like domain. A more precise primer extension assay shows the exact $5^{\prime}$ processing site of J. libera mt-tmRNA (Fig. 3B).

Additional evidences that mt-tmRNAs are functional in mitochondria come from the analysis of the 3' CCA tail, which is essential for the aminoacylation of tRNAs and tmRNAs. Although it is encoded in the tRNA genes of some bacteria, it is post-transcriptionally added by a specific nucleotidyl transferase (CCase) to most bacterial, and to all mitochondrial and eukaryotic cytoplasmic tRNAs (e.g., Chen and Martin 1988; Joyce and Gray 1989; Tomita et al. 1996; Laforest et al. 1997; Schurer et al. 2001). As expected, the tRNA and tmRNA genes in the jakobid mitochondrial genomes lack the $3^{\prime}$ CCA tail. However, ligation of the $5^{\prime}$ and $3^{\prime}$ ends of the mt-tmRNA of J. libera, followed by RT-PCR and sequencing, reveal the addition of the CCA tail on this mt-tmRNA (Fig. 3C). This result also confirms the $5^{\prime}$ end processing of $J$. libera mt-tmRNA, precisely at the predicted nucleotide position, and the recognition of this RNA by a CCase-like enzyme.

\section{RNase P RNA processes precursor tmRNAs of}

\section{$J$. libera and $R$. americana 50394}

One-piece bacterial precursor tmRNAs fold into tRNA-like structures that are processed by the ribonucleoprotein RNase $\mathrm{P}$ to generate the mature $5^{\prime}$ end in the tRNA ${ }^{\text {Ala }}$-like domain (Komine et al. 1994). To verify if RNase $P$ can process precursor mt-tmRNAs, we have performed an in vitro RNA processing assay using the RNase P RNA of $E$. coli, which is known to cleave pre-tRNAs in vitro in the absence of a protein component (Guerrier-Takada and Altman, 1984). For the assay, precursors of the one-piece $J$. libera tmRNA and two-piece R. americana 50394 were synthesized in vitro. Because the importance for efficient processing of base-pairing between leader and trailer sequences is unknown for mt-tmRNAs, two different J. libera pretmRNAs were synthesized. One has a 5' wild-type sequence 
A

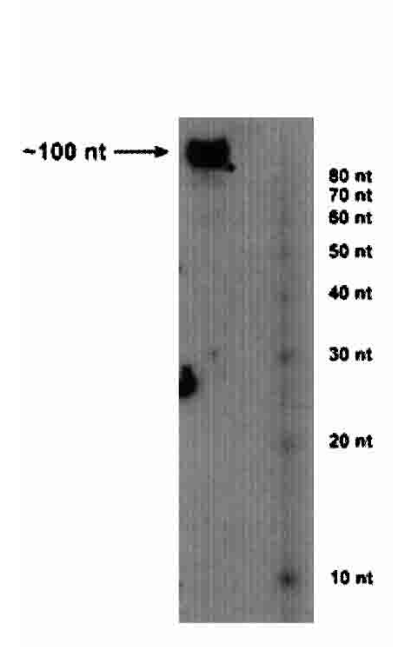

B

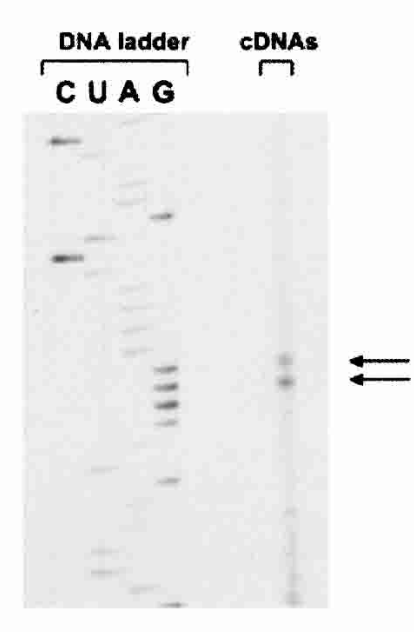

C

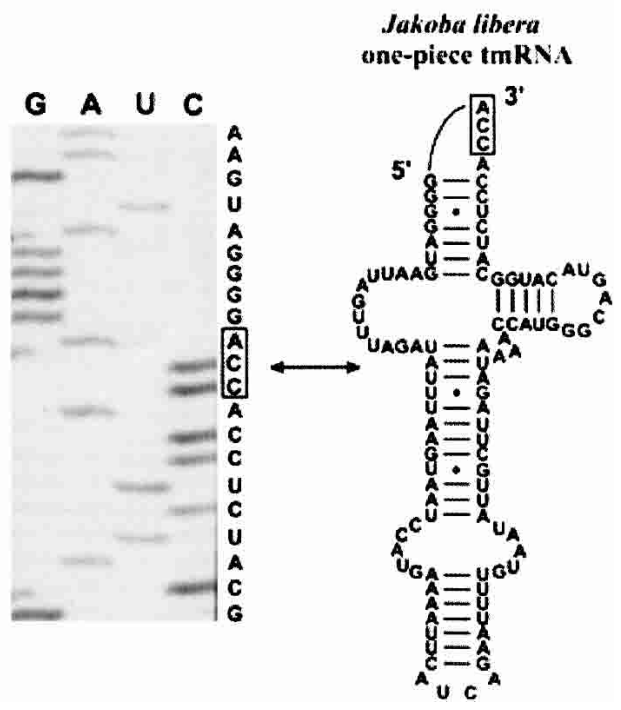

FIGURE 3. Characterization of the mature structure of J. libera tmRNA. (A) A J. libera tmRNA transcript has been detected by Northern blot analysis. The size of this transcript estimated from the RNA ladder (Ambion) is $\sim 100$ nucleotides, which is consistent with its expected size (102 nt) if it is processed like the bacterial tmRNAs. (B) A primer extension assay shows the $5^{\prime}$ end of the mature mitochondrial tmRNA. The result obtained in the next experiment confirms that the upper band is an artifact caused by the reverse transcriptase. (C) Circularization of $J$. libera mt-tmRNA, followed by RT-PCR and sequencing, demonstrate the presence of the nonencoded CCA tail, and confirms the position of the mature $5^{\prime}$ end identified with the primer extension assay.

extension and a CCA tail (Fig. 4A), while the other one contains $5^{\prime}$ and $3^{\prime}$ wild-type sequence extensions (Fig. 4B).

The experimental results indicate that the enzyme cleaves precisely all three synthetic pre-tmRNAs. As expected for the activity of an E. coli RNase P RNA (Guerrier-Takada and Altman, 1984; Guerrier-Takada et al. 1984), the J. libera pre-tmRNA with the CCA tail was processed more efficiently than the one lacking this element (Fig. 4; cf. lanes 3 and 6, and cf. lanes 4 and 7). These results strongly suggest that the mt-tmRNAs of jakobids fold in vivo into structures that are cleaved by RNase P. In the mitochondria of jakobids, they are probably processed at the $5^{\prime}$ end by the mitochondrial RNase P, whose RNA subunit is mtDNAencoded in all jakobids.

\section{J. libera tmRNA is aminoacylated with alanine in vitro}

Another enzyme known to modify eubacterial tmRNAs is alanyl-tRNA synthetase. This enzyme is responsible for the alanylation of the tmRNAs (Komine et al. 1994). This process depends on the presence in all known eubacterial tmRNAs (Williams 2002b) of the tRNA ${ }^{\text {Ala }}$ identity elements (a G-U base pair at the third position of the acceptor arm and $\mathrm{A}$ as the unpaired discriminator base preceding the CCA tail). Because these identity elements are also present in the mt-tmRNAs of jakobids (except S. ecuadoriensis tmRNA, which lacks the G-U base pair), an aminoacylation assay was performed for J. libera tmRNA to verify its alanine-charging ability in vitro. For the assay, we used the partially purified E. coli alanyl-tRNA synthetase.
The mt-tmRNA of J. libera is indeed specifically aminoacylated with alanine in vitro (Fig. 5). However, the efficiency of aminoacylation, as determined by comparison of the aminoacylation plateau, is significantly lower for the mt-tmRNA compared to E. coli tRNA ${ }^{\text {Ala }}(20-30 \%$ of the tRNA $^{\text {Ala }}$ level, depending on the preparation).

\section{DISCUSSION}

The initial suggestion that the mt-tmRNA of $R$. americana might not contain an mRNA-like region was based on the lack of similarity to other tmRNAs outside of the tRNA ${ }^{\mathrm{Ala}}$ like domain (Keiler et al. 2000). An open reading frame (orf64) located immediately downstream of the tRNA ${ }^{\text {Ala }}$ like domain was tentatively excluded as a possible mRNAlike region in part because a potential Shine-Dalgarno sequence is found upstream of the presumed initiation codon. Yet, in the absence of more information on the function of orf64, and the lack of evidence that the initiation codon was correctly inferred, the possibility that this open reading frame encodes a highly derived variant of an mRNA-like region could not be ruled out. Here we provide several lines of evidence to show that structural similarity between mt-tmRNAs and bacterial tmRNAs is indeed restricted to the tRNA ${ }^{\text {Ala }}$-like domain as suggested by Keiler et al. (2000).

Structural characterization of the mt-tmRNA of $J$. libera has confirmed that it is composed in vivo of a single RNA molecule. The existence of a one-piece mttmRNA in J. libera likely results from a secondary, circular 
A

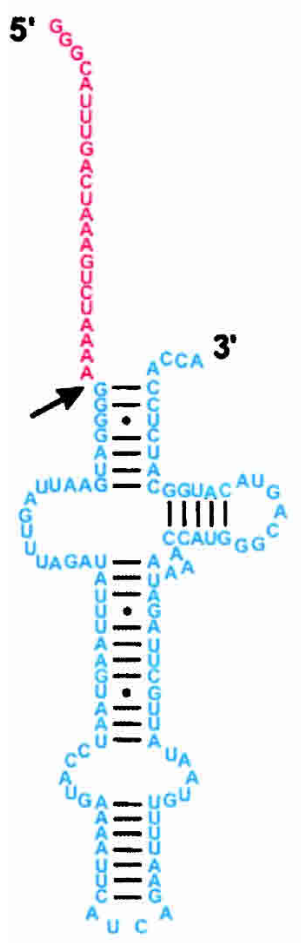

B

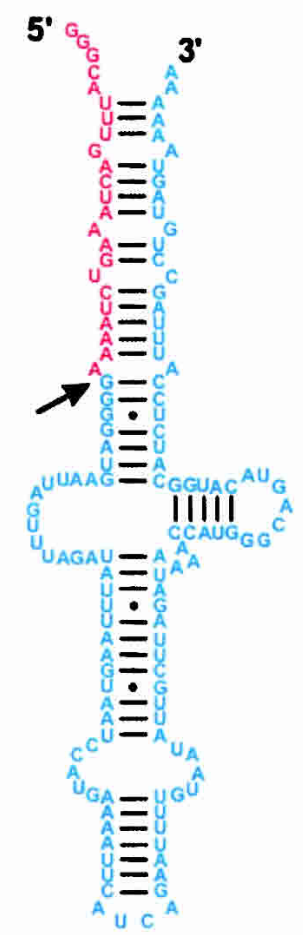

1

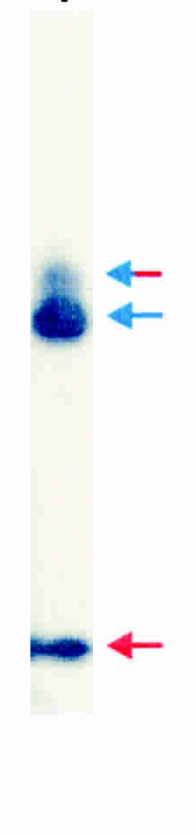

$\begin{array}{lll}2 & 3 & 4\end{array}$

$\begin{array}{lll}5 & 6 & 7\end{array}$
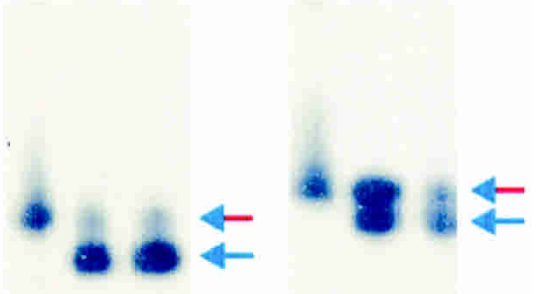

\section{Reclinomonas \\ americana 50394}
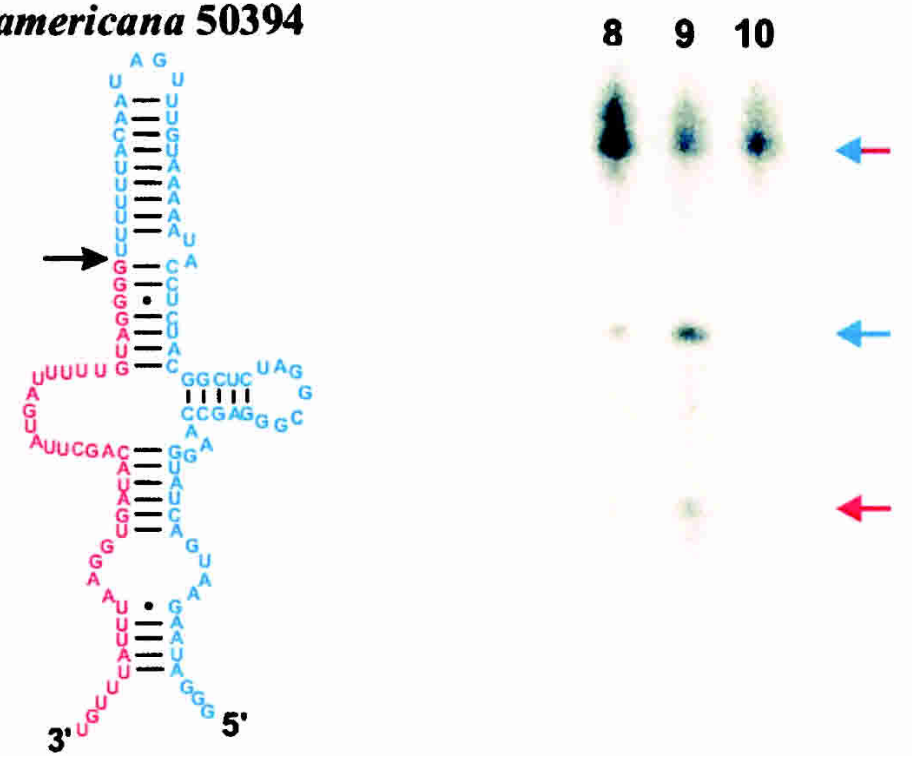

FIGURE 4. In vitro RNase P processing assay. Two different J. libera pre-tmRNAs and one R. americana 50394 pre-tmRNA were produced by in vitro transcription. The two tmRNAs of $J$. libera have a wild-type $5^{\prime}$ sequence extension (red) and either the $3^{\prime}$ CCA tail (A: lanes $\left.2-4\right)$ or a wild-type 3' sequence extension (B: lanes 5-7). $10 \mathrm{nM}$ (lanes 1, 3, 6, and 8), $20 \mathrm{nM}$ (lanes 4 and 7), or $100 \mathrm{nM}$ (lane 9) of E. coli RNase P RNA were used. $R$. americana tRNA $^{\text {Pro }}$ (lane 1 ) and the three pre-tmRNAs incubated in absence of enzyme (lanes 2,5 , and 10 ) served as positive and negative controls, respectively. The three $\mathrm{G}$ residues at the $5^{\prime}$ end of all three pre-tmRNAs are not encoded in the mtDNA genomes, but serve to increase the efficiency of in vitro transcription. The expected sites of cleavage are at the junctions of the red and blue nucleotides (black arrows). In each lane, the upper band (red-blue arrow) is the unprocessed RNA. When a RNA is processed by the enzyme, there is a band (blue arrow) below the upper band, and a band (red arrow) closer to the bottom of the gel.

permutation event of an originally permuted $s s r A$ gene, because all known $\alpha$-Proteobacteria (and by inference, the mitochondrial ancestor) have two-piece tmRNAs. A secondary rearrangement of a ssrA gene, from a permuted to a standard conformation, has never been observed before. 


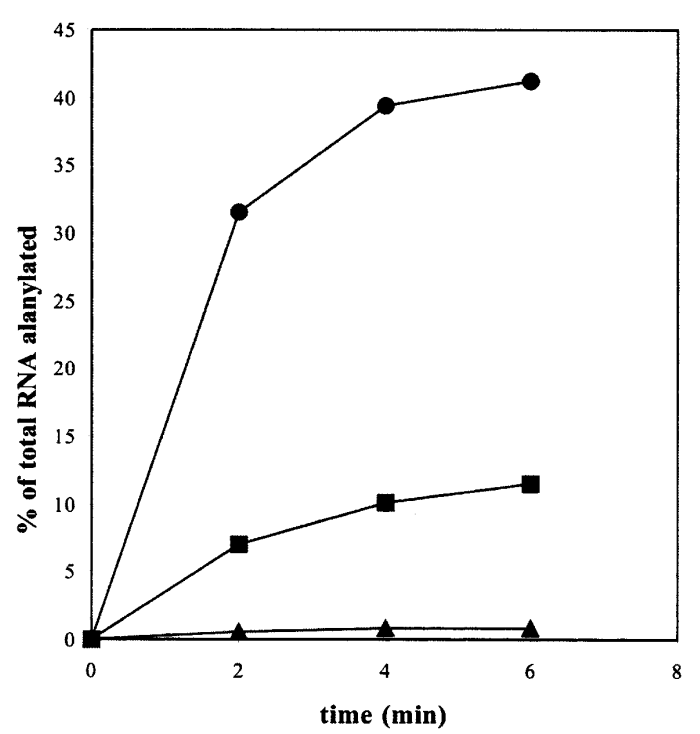

FIGURE 5. In vitro aminoacylation with alanine; 30 pmole of each RNA produced by in vitro transcription were used for the aminoac-

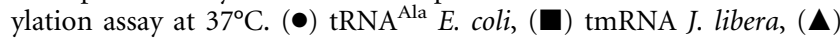
tRNA ${ }^{\text {Cys }}$ E. coli.

J. libera tmRNA is modified post-transcriptionally by the addition of a CCA tail. This strongly suggests that this, and by inference all mitochondrial tmRNAs, are aminoacylated with alanine in vivo. S. ecuadoriensis mt-tmRNA lacks the distinctive $\mathrm{G}-\mathrm{U}$ base pair at the third position of the acceptor arm. This element serves as a major molecular determinant for the alanylation of all known tmRNAs (Komine et al. 1994). Because two mtDNA-encoded tRNAs are edited at their $3^{\prime}$ end in S. ecuadoriensis (Leigh and Lang 2004), it is possible that the G-C base pair present at the third position of the acceptor stem is edited to G-U, although this type of editing usually restores Watson-Crick base pairs rather than eliminating them.

The functionality of mt-tmRNAs is supported by the in vitro aminoacylation of J. libera tmRNA. In our assay, the efficiency of aminoacylation of the mt-tmRNA is significantly lower compared to E. coli tRNA ${ }^{\text {Ala }}$. However, similar results have been obtained in other in vitro aminoacylation assays of bacterial tmRNAs, when compared to tRNA ${ }^{\mathrm{Ala}}$ (Komine et al. 1994; Ushida et al. 1994; Barends et al. 2000). It is known that binding of the protein $\mathrm{SmpB}$ specifically increases the aminoacylation of $E$. coli tmRNA in vitro (Felden et al. 1998; Barends et al. 2001). The crystal structure of the $\mathrm{RNA}^{\text {Ala }}$-like domain of E. coli tmRNA in complex with SmpB shows that this protein makes contact with highly conserved nucleotides located in the variable loop and $3^{\prime}$ end of the D-loop (Gutmann et al. 2003). The conservation of these nucleotides in the mt-tmRNAs (i.e., $G_{18}$, $\mathrm{A}_{19}$, and $\mathrm{A}_{73}$, referring to J. libera numbering) could be an indication that $\mathrm{SmpB}$ is also needed for their cellular role. We have failed to identify a gene encoding a SmpB homolog in completely sequenced jakobid mitochondrial genomes.
The results from the Protist EST Program (http://megasun. bch.umontreal.ca/ pepdb/pep_main.html) will help to determine if such a gene is present in jakobid nuclear genomes.

The in vitro alanylation of the J. libera mt-tmRNA suggests that jakobid tmRNAs interact in vivo with mitochondrial ribosomes. The lack of an mRNA-like region implies that they cannot tag a protein for degradation by switching to an internal reading frame. However, they might have conserved, with some mechanistic modifications, the ability to liberate stalled ribosomes. In bacteria, this activity has been proposed to be more important than peptide tagging for degradation (Withey and Friedman 1999). Recruitment of release factors by mitochondrial tmRNAs has been suggested as a possible mechanistic alternative to switching to the tmRNA reading frame in order to free stalled ribosomes (Keiler et al. 2000).

We have attempted to verify if J. libera mt-tmRNA liberates stalled ribosomes by expressing it from a low-copy plasmid in E. coli X90 (ssrA::cat). This E. coli strain was also transformed with a high-copy plasmid producing a specific mRNA lacking an in-frame stop codon (Keiler et al. 1996). If J. libera mt-tmRNA liberates stalled ribosomes through a transpeptidation reaction in $E$. coli, we might expect to detect a single-alanine tagged reporter protein. Mass spectrometry of the purified protein encoded by the nonstop mRNA has not revealed an alanine tagging (data not shown). Because it has been shown that this reporter protein tagged with alanine is quite stable upon overproduction in E. coli X90 (Williams et al. 1999), we can eliminate the possibility that addition of a single alanine by the mttmRNA has resulted in protein degradation. One explanation for the lack of an alanine addition in our reporter system is a somewhat impaired processing of the precursor mt-tmRNA that was expressed in E. coli, as determined by Northern blot analysis (data not shown). An alternative explanation is that mt-tmRNAs cannot add an alanine, either in jakobid mitochondria or in the heterologous $E$. coli system. If mt-tmRNAs liberate stalled mitochondrial ribosomes, they might be able to do so without being involved in a transpeptidation reaction. Why then do we find the $\mathrm{tRNA}^{\mathrm{Ala}}$ identity elements in mt-tmRNAs? Alanylation might be important to help protect mt-tmRNAs from degradation and to deliver them to the mitochondrial ribosomes.

If mt-tmRNAs do participate in transpeptidation, could the addition of a C-terminal alanine to incomplete proteins mimic the addition of the hydrophobic peptide tag by bacterial tmRNAs? Alanylation as a mechanism of targeting proteins for degradation can probably be excluded because some jakobid mitochondrial genes are predicted to code for proteins with alanine as their last $\mathrm{C}$-terminal amino acid residue. For example, from the 61 protein-coding genes in the J. libera mitochondrial genome, three ( $\operatorname{cox} 3$, nad1, and atp1) are predicted to code for proteins with a C-terminal alanine residue. This observation virtually excludes that a 
single C-terminal alanine, added to a polypeptide by a mttmRNA, would serve as a signal for its degradation. In mitochondria of other eukaryotes, there is no known sequence motif that can trigger protein degradation (Kaser and Langer 2000). Quality control of mitochondrial proteins seems to be dependent only on the folding state of the proteins. Nonassembled or incorrectly folded polypeptides are selectively removed by ATP-dependent proteases in the various mitochondrial subcompartments (Wagner et al. 1994; Pearce and Sherman 1995; Savel'ev et al. 1998). An efficient sensor system for such misfolded proteins in jakobid mitochondria might be sufficient to degrade all partially synthesized proteins freed from stalled ribosomes by the action of mt-tmRNAs. In support of this hypothesis, it has been shown in S. cerevisiae that the mitochondrial inner membrane protease $m$-AAA can carry out proteolysis of partially synthesized mitochondrial translation products (Pajic et al. 1994). Efficient proteolysis of incomplete proteins without the need for a peptide tag might explain the absence of the mRNA-like region in mt-tmRNAs of jakobids.

At the moment, there is no data that demonstrates the assumed functional role of mt-tmRNAs, that is, that these highly derived RNA molecules have at least retained part of the functions of bacterial tmRNAs. The identification of a SmpB protein homolog in jakobid mitochondria, and biochemical studies of the purified, native tmRNA-protein complex will be required to address this question.

\section{MATERIALS AND METHODS}

\section{Sequences}

Mitochondrial tmRNA sequences were identified in ongoing jakobid sequencing projects of the Organelle Genome Megasequencing Project. J. libera cells were grown at $25^{\circ} \mathrm{C}$ in $\mathrm{F} / 2$ medium, all other jakobids were grown at $25^{\circ} \mathrm{C}$ in WCL medium (http://megasun.bch.umontreal.ca/People/lang/FMGP/methods/).

\section{Purification of small mitochondrial RNAs}

Mitochondrial DNA and RNAs from jakobids were extracted from partially purified mitochondria obtained after breaking the cells with glass beads. Mitochondria were separated from the cell debris by differential centrifugations and lysed by incubation with $1 \%$ SDS and $100 \mu \mathrm{g} / \mathrm{mL}$ of Proteinase $\mathrm{K}$ for $1 \mathrm{~h}$ at $25^{\circ} \mathrm{C}$. The mitochondrial fraction was placed over a $30 \%$ glycerol solution and the small mitochondrial RNAs (including tRNAs, tmRNA, and 5S rRNA) were separated from the large RNAs and DNA by ultracentrifugation $\left(240,000 \times g, 3 \mathrm{~h}, 10^{\circ} \mathrm{C}\right)$. Small mitochondrial RNAs were collected from the upper part of the glycerol solution and precipitated twice with $95 \%$ ethanol/0.5 M ammonium acetate, washed with $80 \%$ ethanol, and stored at $-70^{\circ} \mathrm{C}$ in DEPC-treated water.

\section{Northern blot analysis and primer extension assay}

The oligonucleotide (5'-TACTGCCCATGGTTTTATCTA) used for the Northern blot analyses and primer extension assays was $5^{\prime}$-labeled with $\left(\gamma-{ }^{32} \mathrm{P}\right)$-ATP (Perkin-Elmer) and T4 Polynucleotide Kinase (USB). For Northern blot analyses, $500 \mathrm{ng}$ of small mitochondrial RNAs of $J$. libera were separated on a $10 \%-12 \%$ polyacrylamide/ $8 \mathrm{M}$ urea gel. The separated RNAs were electroblotted onto a Hybond-N membrane (Amersham Pharmacia Biotech). Prehybridization was performed in $1 \mathrm{mM}$ EDTA, $6 \times$ SSPE, $0.2 \%$ SDS, $7.5 \times$ Denhardt's reagent for $2 \mathrm{~h}$, and hybridization in $6 \times$ SSPE overnight. The membrane was washed twice for $10 \mathrm{~min}$ at room temperature in $6 \times \mathrm{SSPE}, 15 \mathrm{~min}$ at hybridization temperature in $6 \times \mathrm{SSPE}$, and $10 \mathrm{~min}$ at hybridization temperature in $6 \times$ SSPE. The membrane was exposed overnight at $-70^{\circ} \mathrm{C}$. For the primer extension assay, cDNA synthesis and preparation of the DNA ladder was performed as described (Sambrook et al. 1989). The cDNAs and the DNA ladder were migrated on a $5 \%$ polyacrylamide/8M urea gel.

\section{RNA circularization and RT-PCR}

Circularization of mitochondrial RNAs, and cDNAs synthesis was based on the protocol of Yokobori and Pääbo (Yokobori and Pääbo 1995). The oligonucleotide used for cDNA synthesis of $J$. libera RNAs was 5'-GGATTACTTAAATATCTAAACTAA, and cDNAs were PCR-amplified with the additional primer 5'-GCT TAGATAAAACCATGGGCAGTA. The resulting PCR fragment of appropriate size was purified on an agarose gel, cloned into the EcoRV restriction site of the phagemid pFBS (B.F. Lang, unpubl.), and sequenced by the dideoxy chain-termination method.

\section{In vitro RNase $\mathbf{P}$ RNA processing assay}

The ssrA genes of J. libera and R. americana 50394 was PCRamplified with oligonucleotides to produce DNA fragments that were used to generate precursor mt-tmRNAs. For J. libera, two different pre-tmRNAs were synthesized (for details, see the RNA structures in Fig. 4). They both have a wild-type $5^{\prime}$ sequence extension, and (1) a wild-type $3^{\prime}$ sequence extension or (2) a $3^{\prime}$ CCA tail that is required for more efficient processing by $E$. coli RNase P (Liu and Altman 1996). The run-off transcription reaction was performed as described (Yuan et al. 1992). The precursor tmRNAs were purified on a $10 \%$ polyacrylamide/8M urea gel and quantified in a liquid scintillation counter.

The expression plasmid carrying the E. coli RNase P RNA gene (generously provided by Sidney Altman) was used for run-off transcription of the ribozyme. The resulting RNA was purified on a G50 column, precipitated twice with $95 \%$ ethanol/0.5 M ammonium acetate, washed with $80 \%$ ethanol, and stored in DEPCtreated water at $-80^{\circ} \mathrm{C}$. For the assays, the RNA was first activated by heating the sample to $65^{\circ} \mathrm{C}$ for $5 \mathrm{~min}$, and cooling it slowly to room temperature in a buffer containing $10 \mathrm{mM}$ Tris- $\mathrm{HCl}, \mathrm{pH} 7.5$, $10 \mathrm{mM} \mathrm{MgCl}_{2}, 100 \mathrm{mM} \mathrm{NH} \mathrm{ml}_{4} \mathrm{Cl}$ tmRNA substrates $(1000 \mathrm{cpm})$ were incubated at $37^{\circ} \mathrm{C}$ in $10 \mathrm{mM}$ Tris- $\mathrm{HCl}, \mathrm{pH} 7.5,100 \mathrm{mM}$ $\mathrm{MgCl}_{2}, 100 \mathrm{mM} \mathrm{NH}_{4} \mathrm{Cl}, 4 \%$ PEG , and in the presence of different RNase P RNA concentrations $(10 \mathrm{nM}, 20 \mathrm{nM}$ or $100 \mathrm{nM})$. The total volume of the reaction was $10 \mu \mathrm{L}$. After $1 \mathrm{~h}, 10 \mu \mathrm{L}$ of loading buffer was added, and the sample was heated at $75^{\circ} \mathrm{C}$ for $2 \mathrm{~min}$ before loading on a $8 \%$ polyacrylamide/ $8 \mathrm{M}$ urea gel.

\section{In vitro aminoacylation assay}

Oligonucleotides were designed to PCR-amplify the mitochondrial ssrA gene of $J$. libera, and tRNA ${ }^{\mathrm{Ala}}$ and tRNA ${ }^{\mathrm{Cys}}$ genes from E. coli. 
For amplification of the J. libera ssrA sequence, the oligonucleotide was designed such that the amplified sequence would include a (nonencoded) 3' CCA tail. The PCR fragments were cloned into the EcoR5 restriction site of pFBS and sequenced. The plasmids were digested with MvaI, and subsequently used in run-off transcription. The resulting RNAs were purified on a denaturing $15 \%$ polyacrylamide/ $8 \mathrm{M}$ urea gel, and quantified by spectrophotometry.

The partial purification of E. coli alanyl-tRNA synthase, and the aminoacylation reactions were performed as described (Komine et al. 1994), with slight modifications: $1.5 \mathrm{~g}$ of wet weight $E$. coli cells were collected from an overnight culture and sonicated. The enzyme was partially purified from an S100 extract by ion-exchange chromatography (on DEAE-Amersham Pharmacia Biotech). The fraction containing the enzyme was desalted, concentrated to 200 $\mu \mathrm{L}$, and partially purified from smaller proteins by using Amicon Ultra-15 Centrifugal Filter Units, Membrane NMWL 100,000 (Millipore). Glycerol was added to the enzyme solution to reach a final concentration of $50 \%$, and stored at $-20^{\circ} \mathrm{C}$. For the aminoacylation reactions, the RNAs were activated in water by heating for $5 \mathrm{~min}$ at $90^{\circ} \mathrm{C}$, followed by rapid cooling on ice-cold water.

\section{ACKNOWLEDGMENTS}

We thank K.P. Williams for critically reading the manuscript, for supplying several plasmid constructs and the E. coli strain X90 ssrA1::cat, and for his help with the functional assay. This work was supported by grants from the Canadian Institute of Health Research (MOP-42475; B.F.L.), and "Le Fond Quebecois de la Recherche sur la Nature et les Technologies" (NATEQ; Y.J.). Salary and interaction support from the Canadian Institute for Advanced Research (B.F.L.) and supply of laboratory equipment and informatics infrastructure by Genome Quebec/Canada is gratefully acknowledged. This project was supported by equipment grants from Sun Microsystems and LiCor.

The publication costs of this article were defrayed in part by payment of page charges. This article must therefore be hereby marked "advertisement" in accordance with 18 USC section 1734 solely to indicate this fact.

Received November 10, 2003; accepted December 29, 2003.

\section{REFERENCES}

Barends, S., Wower, J., and Kraal, B. 2000. Kinetic parameters for tmRNA binding to alanyl-tRNA synthetase and elongation factor Tu from Escherichia coli. Biochemistry 39: 2652-2658.

Barends, S., Karzai, A.W., Sauer, R.T., Wower, J., and Kraal, B. 2001. Simultaneous and functional binding of SmpB and EF-Tu-TP to the alanyl acceptor arm of tmRNA. J. Mol. Biol. 314: 9-21.

Chen, J.Y. and Martin, N.C. 1988. Biosynthesis of tRNA in yeast mitochondria. An endonuclease is responsible for the $3^{\prime}$-processing of tRNA precursors. J. Biol. Chem. 263: 13677-13682.

Felden, B., Hanawa, K., Atkins, J.F., Himeno, H., Muto, A., Gesteland, R.F., McCloskey, J.A., and Crain, P.F. 1998. Presence and location of modified nucleotides in Escherichia coli tmRNA: Structural mimicry with tRNA acceptor branches. EMBO J. 17: 3188-3196.

Felden, B., Gesteland, R.F., and Atkins, J.F. 1999. Eubacterial tmRNAs: Everywhere except the alpha-proteobacteria? Biochim. Biophys. Acta 1446: 145-148.

Gaudin, C., Zhou, X., Williams, K.P., and Felden, B. 2002. Two-piece
tmRNA in cyanobacteria and its structural analysis. Nucleic Acids Res. 30: 2018-2024.

Gueneau de Novoa, P. and Williams, K.P. 2004. The tmRNA website: Reductive evolution of tmRNA in plastids and other endosymbionts. Nucleic Acids Res. 32: D104-D108.

Guerrier-Takada, C. and Altman, S. 1984. Catalytic activity of an RNA molecule prepared by transcription in vitro. Science 223: 285-286.

Guerrier-Takada, C., McClain, W.H., and Altman, S. 1984. Cleavage of tRNA precursors by the RNA subunit of E. coli ribonuclease P (M1 RNA) is influenced by $3^{\prime}$-proximal CCA in the substrates. Cell 38: $219-224$.

Gutmann, S., Haebel, P.W., Metzinger, L., Sutter, M., Felden, B., and Ban, N. 2003. Crystal structure of the transfer-RNA domain of transfer-messenger RNA in complex with SmpB. Nature 424: 699703.

Hanawa-Suetsugu, K., Takagi, M., Inokuchi, H., Himeno, H., and Muto, A. 2002. SmpB functions in various steps of trans-translation. Nucleic Acids Res. 30: 1620-1629.

Joyce, P.B. and Gray, M.W. 1989. Chloroplast-like transfer RNA genes expressed in wheat mitochondria. Nucleic Acids Res. 17: 54615476.

Karzai, A.W., Susskind, M.M., and Sauer, R.T. 1999. SmpB, a unique RNA-binding protein essential for the peptide-tagging activity of SsrA (tmRNA). EMBO J. 18: 3793-3799.

Karzai, A.W., Roche, E.D., and Sauer, R.T. 2000. The SsrA-SmpB system for protein tagging, directed degradation and ribosome rescue. Nat. Struct. Biol. 7: 449-455.

Kaser, M. and Langer, T. 2000. Protein degradation in mitochondria. Semin. Cell Dev. Biol. 11: 181-190.

Keiler, K.C., Waller, P.R., and Sauer, R.T. 1996. Role of a peptide tagging system in degradation of proteins synthesized from damaged messenger RNA. Science 271 990-993.

Keiler, K.C., Shapiro, L., and Williams, K.P. 2000. tmRNAs that encode proteolysis-inducing tags are found in all known bacterial genomes: A two-piece tmRNA functions in Caulobacter. Proc. Natl. Acad. Sci. 97: 7778-7783.

Komine, Y., Kitabatake, M., Yokogawa, T., Nishikawa, K., and Inokuchi, H. 1994. A tRNA-like structure is present in 10Sa RNA, a small stable RNA from Escherichia coli. Proc. Natl. Acad. Sci. $919223-$ 9227.

Laforest, M.J., Roewer, I., and Lang, B.F. 1997. Mitochondrial tRNAs in the lower fungus Spizellomyces punctatus: tRNA editing and UAG "stop" codons recognized as leucine. Nucleic Acids Res. 25: 626-632.

Lang, B.F., Burger, G., O'Kelly, C.J., Cedergren, R., Golding, G.B., Lemieux, C., Sankoff, D., Turmel, M., and Gray, M.W. 1997. An ancestral mitochondrial DNA resembling a eubacterial genome in miniature. Nature 387: 493-497.

Leigh, J. and Lang, B.F. 2004. Mitochondrial 3' tRNA editing in the jakobid Seculamonas ecuadoriensis: A novel mechanism and implications for tRNA processing. RNA (this issue).

Liu, F. and Altman, S. 1996. Requirements for cleavage by a modified RNase P of a small model substrate. Nucleic Acids Res. 24: 2690-2696.

O'Kelly, C.J. 1993. The jakobid flagellates: Structural features of Jakoba, Reclinomonas and Histiona and implications for the early diversification of eukaryotes. J. Eukaryot. Microbiol. 40: 627-636.

O’Kelly. C.J., Farmer, M.A., and Nerad, T.A. 1999. Ultrastructure of Trimastix pyriformis (Klebs) Bernard et al.: Similarities of Trimastix species with retortamonad and jakobid flagellates. Protist 150: 149162.

Pajic, A., Tauer, R., Feldmann, H., Neupert, W., and Langer, T. 1994. Yta10p is required for the ATP-dependent degradation of polypeptides in the inner membrane of mitochondria. FEBS Lett. 353: 201-206.

Pearce, D.A. and Sherman, F. 1995. Degradation of cytochrome oxidase subunits in mutants of yeast lacking cytochrome $c$ and suppression of the degradation by mutation of yme1. J. Biol. Chem. 270: 20879-20882.

Sambrook, J., Fritsch, E.F., and Maniatis, T. 1989. Molceular cloning: A 
laboratory manual. Cold Spring Harbor Laboratory Press, Cold Spring Harbor, NY.

Savel'ev, A.S., Novikova, L.A., Kovaleva, I.E., Luzikov, V.N., Neupert, W., and Langer, T. 1998. ATP-dependent proteolysis in mitochondria. m-AAA protease and PIM1 protease exert overlapping substrate specificities and cooperate with the mtHsp70 system. J. Biol. Chem. 273: 20596-20602.

Schurer, H., Schiffer, S., Marchfelder, A., and Morl, M. 2001. This is the end: Processing, editing and repair at the tRNA 3 '-terminus. Biol. Chem. 382: 1147-1156.

Tomita, K., Ueda, T., and Watanabe, K. 1996. RNA editing in the acceptor stem of squid mitochondrial tRNA(Tyr). Nucleic Acids Res. 24: 4987-4991.

Ushida, C., Himeno, H., Watanabe, T., and Muto, A. 1994. tRNA-like structures in 10Sa RNAs of Mycoplasma capricolum and Bacillus subtilis. Nucleic Acids Res. 22: 3392-3396.

Wagner, I., Arlt, H., van Dyck, L., Langer, T., and Neupert, W. 1994. Molecular chaperones cooperate with PIM1 protease in the degradation of misfolded proteins in mitochondria. EMBO J. 13: 5135-
5145.

Williams, K.P. 2002a. Descent of a split RNA. Nucleic Acids Res. 30: $2025-2030$.

2002b. The tmRNA Website: Invasion by an intron. Nucleic Acids Res. 30: 179-182.

Williams, K.P., Martindale, K.A., and Bartel, D.P. 1999. Resuming translation on tmRNA: A unique mode of determining a reading frame. $E M B O ~ J .18: 5423-5433$.

Withey, J. and Friedman, D. 1999. Analysis of the role of trans-translation in the requirement of tmRNA for lambdaimmP22 growth in Escherichia coli. J. Bacteriol. 181: 2148-2157.

Wu, L.F., Ize, B., Chanal, A., Quentin, Y., and Fichant, G. 2000. Bacterial twin-arginine signal peptide-dependent protein translocation pathway: evolution and mechanism. J. Mol. Microbiol. Biotechnol. 2: 179-189.

Yokobori, S. and Pääbo, S. 1995. Transfer RNA editing in land snail mitochondria. Proc. Natl. Acad. Sci. 92: 10432-10435.

Yuan, Y., Hwang, E.S., and Altman, S. 1992. Targeted cleavage of mRNA by human RNase P. Proc. Natl. Acad. Sci. 89: 8006-8010. 

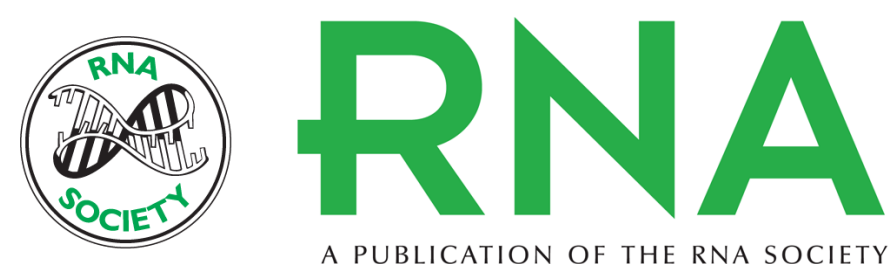

A PUBLICATION OF THE RNA SOCIETY

\section{Loss of the mRNA-like region in mitochondrial tmRNAs of jakobids}

\section{YANNICK JACOB, ELIAS SEIF, PIERRE-OLIVIER PAQUET, et al.}

RNA 2004 10: 605-614

References This article cites 36 articles, 12 of which can be accessed free at:

http://rnajournal.cshlp.org/content/10/4/605.full.html\#ref-list-1

License

Email Alerting Receive free email alerts when new articles cite this article - sign up in the box at the Service top right corner of the article or click here. 